\title{
Using graphene to simplify the adsorption of methane on shale in MD simulations
}

\author{
Kui Lin, Quanzi Yuan, Ya-Pu Zhao* \\ State Key Laboratory of Nonlinear Mechanics, Institute of Mechanics, Chinese Academy of Sciences, Beijing 100190, China \\ School of Engineering Science, University of Chinese Academy of Sciences, Beijing 100049, China
}

\section{A R T I C L E I N F O}

\section{Article history:}

Received 16 December 2016

Received in revised form 2 March 2017

Accepted 3 March 2017

Available online 17 March 2017

\section{Keywords:}

Graphene

Shale

Adsorption isotherms

Adsorption heat

Simulations

\begin{abstract}
A B S T R A C T
In this paper, we explored material similarity between graphene and shale for methane $\left(\mathrm{CH}_{4}\right)$ adsorption in the shale gas recovery simulations. The reasons of choosing graphene to model shale have been clarified. Through theoretical analysis, we obtained the attenuation law of interaction potential between $\mathrm{CH}_{4}$ and multilayer graphene. It indicates the adsorption energy of $\mathrm{CH}_{4}$ on monolayer graphene is closest to that on shale. The limiting heat of adsorption of $\mathrm{CH}_{4}$ on graphene was calculated by molecular dynamics (MD) simulation. The adsorption isotherms and adsorption heats on the monolayer graphene, whose width of the slit pore ranges from $2 \mathrm{~nm}$ to $11 \mathrm{~nm}$, were calculated by using grand canonical Monte Carlo (GCMC) simulations at different temperatures. The computed adsorption heat is validated by experimental data, which indicates that the adsorption properties of $\mathrm{CH}_{4}$ on shale are quite similar with that of $\mathrm{CH}_{4}$ on graphene. Our study may provide a direct evidence of using graphene in modeling shale in simulating the shale gas adsorption/desorption.
\end{abstract}

(c) 2017 Elsevier B.V. All rights reserved.

\section{Introduction}

As a unconventional gas resource, shale gas plays an increasingly important role in renewable energy, because of its great reserves throughout the world and its clean when burned [1,2]. Most shale gas production in North America attributes to the development of horizontal drilling and fracking technology [3,4]. Also shale gas has been extensively explored in Australia, Europe and China in recent years [5]. Even though thousands of shale gas wells are in production around the world, there are still many difficulties in shale gas exploitation technology [6-10], and the thermodynamic properties of shale gas are still poorly understood. Hence, researchers have increasingly tried to explore the properties of shale gas and find out an efficient way in enhancing shale gas recovery (ESGR) [11-14]. Experiment is a direct way to explore the properties of shale gas in shale [15-19], but is difficult to achieve high-pressure conditions of methane $\left(\mathrm{CH}_{4}\right)$ as the same of real pressure (20-30 MPa) in shale. And most pressure condition in experiment was under $20 \mathrm{MPa}$ [20]. In addition, earlier studies show that shale gas adsorbs in the nanopores [21-23]. Therefore, it is difficult to experimentally explore the microscopic

\footnotetext{
* Corresponding author at: State Key Laboratory of Nonlinear Mechanics, Institute of Mechanics, Chinese Academy of Sciences, Beijing 100190, China.

E-mail address: yzhao@imech.ac.cn (Y.-P. Zhao).
}

mechanisms of shale gas adsorption in nanopores. Simulation provides an efficient and inexpensive way to investigate the microscopic properties of $\mathrm{CH}_{4}$ in shale. However, the components and microstructure of the shale are very complex. For convenience of calculations, we need to find a simple geometry yet similar properties material as a model of shale in the shale gas recovery simulations.

Molecular dynamics (MD) simulations have been extensively conducted to investigate shale gas adsorption. Firoozabadi made a great contribution to the research of hydrocarbons energy production and illuminated the use of thermodynamics in reservoir and transportation of shale gas, and MD simulations were performed in his research [24]. In previous simulations, $\mathrm{CH}_{4}$ was considered under thermodynamic equilibrium in three-dimensional periodic orthorhombic pore geometry consisting of upper and lower pore-walls made of graphene [25]. Coal and shale both require a thorough understanding of the $\mathrm{CO}_{2}$ adsorption properties in microporous carbon-based materials. Wilcox et al. investigated the adsorption of $\mathrm{CO}_{2}$ in microporous carbons. They explored $\mathrm{CH}_{4}$ adsorption properties on graphitic surfaces as an initial model of coal and kerogen of gas shale [26,27]. The adsorption behavior of oil within nanoscale carbonaceous slits of shale systems was studied by using MD simulation, with graphene sheets as the model of shale [28]. Recently, the atomic mechanisms and adsorption properties of $\mathrm{CH}_{4}$ on graphene (or carbon nanopores) have been inves- 
tigated [29-32]. Graphene is widely used in the researches of shale and coal. Even though many researchers chose graphene as a model of shale or coal, the reasons for this choice are not clear or the evidence remains insufficient. Hence, material similarity between graphene and shale for $\mathrm{CH}_{4}$ adsorption need to be explored in detail.

In this paper, thermodynamic properties of the $\mathrm{CH}_{4}$ adsorption on graphene are investigated and the results are compared with the experiment. Firstly, we used theoretical analysis to investigate the interaction potential between $\mathrm{CH}_{4}$ and graphene, the effect of the number of graphene layers on the interaction potential was explored. Secondly, we provide a way to calculate the limiting heat of adsorption of $\mathrm{CH}_{4}$ on graphene, and compared the limiting heat with experimental results. Thirdly, the grand canonical Monte Carlo (GCMC) simulations were performed to predict the $\mathrm{CH}_{4}$ adsorption isotherm at $300 \mathrm{~K}, 320 \mathrm{~K}, 340 \mathrm{~K}$ and $360 \mathrm{~K}$, and the fugacity from $1 \mathrm{MPa}$ to $40 \mathrm{MPa}$, with $2 \mathrm{~nm}, 3 \mathrm{~nm}, 5 \mathrm{~nm}, 7 \mathrm{~nm}$, $9 \mathrm{~nm}$ and $11 \mathrm{~nm}$ slit pore sizes. And we provide a way to transform fugacity and absolute adsorption into pressure and excess adsorption. Finally, the isoteric adsorption heats of $\mathrm{CH}_{4}$ in multiple graphene slit pore sizes at different temperatures were investigated. Our results and related analyses may help to understand the $\mathrm{CH}_{4}$ adsorption on graphene. More importantly, the results provide a strong evidence of using graphene in modeling shale in simulating the shale gas adsorption/desorption. This study aims to quantify whether graphene may be used to represent the wall boundaries of nanopores in shale gas adsorption measurements in MD simulations. It presents future researchers to simplify the description of shale nanostructure with an equivalent slit pore consisting of graphene.

\section{Methods}

MD simulations implemented in LAMMPS [33] have been carried out. We simulated the limiting adsorption heat of $\mathrm{CH}_{4}$ on graphene adopting consistent valence force-field (CVFF) [34], which is based on the ab initio calculations and experiments. The total potential energy consists of the bond energy $E_{\mathrm{b}}$ and nonbond energy $E_{\mathrm{ij}}$. $E_{\mathrm{b}}$ is the sum of bond and angle energy. $E_{\mathrm{ij}}$ is the interaction potential between two atoms $\mathrm{i}$ and $\mathrm{j}$, which is Lennard-Jones (LJ) energies:

$E_{\mathrm{ij}}=4 \varepsilon_{\mathrm{ij}}\left[\left(\frac{\sigma_{\mathrm{ij}}}{r_{\mathrm{ij}}}\right)^{12}-\left(\frac{\sigma_{\mathrm{ij}}}{r_{\mathrm{ij}}}\right)^{6}\right]$,

where $\varepsilon_{\mathrm{ij}}$ is the depth of the potential well, $\sigma_{\mathrm{ij}}$ is the zero-crossing distance for the potential, $r_{\mathrm{ij}}$ is the distance between the two atoms. The values of $\sigma_{\mathrm{ij}}$ and $\varepsilon_{\mathrm{ij}}$ between two species were calculated by the Lorentz-Berthelot (LB) rule: $\sigma_{\mathrm{ij}}=\left(\sigma_{\mathrm{i}}+\sigma_{\mathrm{j}}\right) / 2, \quad \varepsilon_{\mathrm{ij}}=\sqrt{\varepsilon_{\mathrm{i}} \cdot \varepsilon_{\mathrm{j}}}$. The whole system was modeled in NVT ensemble (constant number of atoms, volume and temperature) with Nose/Hoover method and the time step was $1 \mathrm{fs}$, to regulate the temperature at $300 \mathrm{~K}$. The internal energy variation of the system was calculated in the $\mathrm{CH}_{4}$ adsorption processes. The limiting heat of adsorption is the adsorption heat as the pressure goes to zero. Hence we performed $\mathrm{CH}_{4}$ molecules in a simulation box that is big enough, to calculate the limiting heat of adsorption of $\mathrm{CH}_{4}$ on graphene.

GCMC method was performed to investigate the adsorption isotherms and adsorption heat of $\mathrm{CH}_{4}$ on the graphene. The grand canonical ensemble is an ensemble that has constant volume $V$, temperature $T$ and chemical potential $\mu$. In the simulation processes of gas adsorption, the equilibrium conditions are the temperature and chemical potential being equal in different phase (adsorption phase and gas phase). The CVFF was adopted in MC simulations. For each simulation, we performed 10,000 runs for equilibrium and 100,000 runs for production. The vdW interactions in these simulations were calculated with a cutoff of $12.5 \AA$, and the electrostatic interactions were described by Ewald method and the cutoff is $12.5 \AA$. In our simulations, it was fugacity rather than pressure that was used for predicting adsorption isotherms, adsorption heat and other thermodynamics properties.

\section{Results and discussions}

\subsection{Limiting heat of adsorption of $\mathrm{CH}_{4}$ on graphene}

When the amount adsorbed approaches zero, the isosteric heat of adsorption is called the limiting heat of adsorption. It is a representative thermal effect of the adsorption. The limiting heat of adsorption can be evaluated from Henry constants if they are available for several temperatures, and the Henry constant varies with temperature following the van't Hoff equation [35]:

$\frac{\mathrm{d} \ln K}{\mathrm{~d} T}=\frac{\Delta H_{0}}{R T^{2}}$,

where $K$ is the Henry constant, $T$ is the absolute temperature, $\Delta H_{0}$ is the difference of molar enthalpy between adsorption states and gas states, $R$ is the ideal gas constant. The limiting heat of adsorption is $-\Delta H_{0}$. Integrating Eq. (2), we can obtain

$\ln K=-\frac{\Delta H_{0}}{R T}+C$.

Hence, by plotting the variation of $\ln K$ with $1 / T$, the limiting heat of adsorption can be evaluated from the slope of the plot. This method is widely used in experiment for evaluating the limiting heat of adsorption.

However, as for simulations in this case, we found a direct way to calculate the limiting heat of adsorption. In the analysis of adsorption process, it is necessary to distinguish adsorbed molecules from gas phase. For the convenience of thermodynamic analysis, Gibbs defined a mathematical dividing surface between the gas phase and adsorbent as shown in Fig. 1. According to the Gibbs model of adsorption, any extensive thermodynamics quantity $X$ may be written as the sum of the gas phase, the adsorbate and the adsorbent:

$X=X^{\mathrm{g}}+X^{\mathrm{a}}+X^{\mathrm{s}}$.

After adsorbing on the adsorbent, the total internal energy $U$ of solid phase is

$U=T S-p V+\sum_{\mathrm{i}=1}^{C} \mu_{\mathrm{i}} n_{\mathrm{i}}+\mu$,

where $S$ is entropy, $p$ is the pressure, $\mu_{\mathrm{i}}$ and $n_{\mathrm{i}}$ are the chemical potential and the number of moles of adsorbate i, respectively, $\mu$

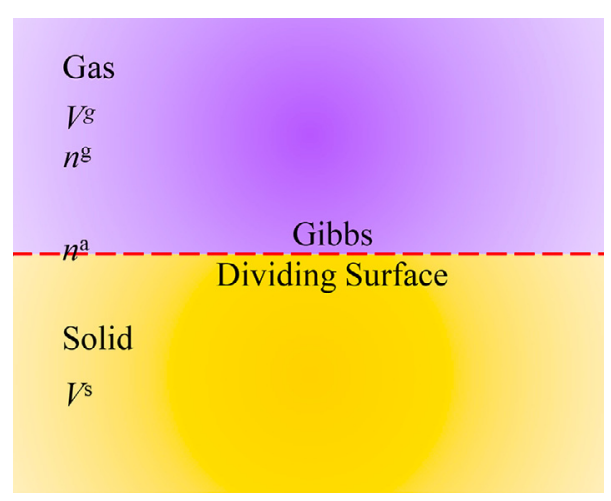

Fig. 1. Gibbs model of interface. 
is the chemical potential of the solid adsorbent. For the adsorbent in its pure standard state at the same pressure and temperature, the total internal energy $U^{\mathrm{s}}$ of solid phase is

$U^{s}=T S^{s}-p V^{s}+\mu^{s}$.

Hence, the extensive quantities of the adsorption phase are obtained

$$
\begin{aligned}
& U^{\mathrm{a}}=U-U^{\mathrm{s}} \\
& S^{\mathrm{a}}=S-S^{\mathrm{s}} \\
& n_{\mathrm{i}}^{\mathrm{a}}=n_{\mathrm{i}} \\
& V^{\mathrm{a}}=V-V^{\mathrm{s}}=0,
\end{aligned}
$$

the volume $V^{\mathrm{a}}$ of adsorption phase is zero for the Gibbs dividing surface. Subtracting Eq. (6) from Eq. (5), and substituting Eq. (7), the internal energy $U^{\mathrm{a}}$ of the adsorption phase is obtained

$U^{\mathrm{a}}=T S^{\mathrm{a}}+\sum_{\mathrm{i}=1}^{C} \mu_{\mathrm{i}} n_{\mathrm{i}}^{\mathrm{a}}+\psi$,

where $\psi=\mu-\mu^{\mathrm{s}}$ is the surface potential. The surface potential is zero when no adsorption occurs.

The enthalpy of a system is defined as

$$
H=U+p V \text {. }
$$

From Eqs. (8), (9) and $V^{\mathrm{a}}=0$

$$
\begin{aligned}
H^{\mathrm{a}} & =T S^{\mathrm{a}}+\sum_{\mathrm{i}=1}^{c} \mu_{\mathrm{i}} n_{\mathrm{i}}^{\mathrm{a}}+\psi+p V^{\mathrm{a}} \\
& =T S^{\mathrm{a}}+\sum_{\mathrm{i}=1}^{c} \mu_{\mathrm{i}} n_{\mathrm{i}}^{\mathrm{a}}+\psi .
\end{aligned}
$$

From Eqs. (8) and (10)

$U^{\mathrm{a}}=H^{\mathrm{a}}$

Before the adsorption happening, the internal energy $U_{0}^{\mathrm{a}}$ and the enthalpy $H_{0}^{\mathrm{a}}$ of adsorption phase are zero. Hence, the total internal energy $U_{0}$ and the total enthalpy $H_{0}$ are obtained

$U_{0}=U_{0}^{\mathrm{a}}+U_{0}^{\mathrm{g}}+U_{0}^{\mathrm{s}}=U_{0}^{\mathrm{g}}+U_{0}^{\mathrm{s}}$

$H_{0}=H_{0}^{\mathrm{a}}+H_{0}^{\mathrm{g}}+H_{0}^{\mathrm{s}}=H_{0}^{\mathrm{g}}+H_{0}^{\mathrm{s}}$.

After adsorption, the total internal energy $U_{\mathrm{t}}$ and the total enthalpy $H_{\mathrm{t}}$ are obtained

$U_{\mathrm{t}}=U_{\mathrm{t}}^{\mathrm{a}}+U_{\mathrm{t}}^{\mathrm{g}}+U_{\mathrm{t}}^{\mathrm{s}}$

$H_{\mathrm{t}}=H_{\mathrm{t}}^{\mathrm{a}}+H_{\mathrm{t}}^{\mathrm{g}}+H_{\mathrm{t}}^{\mathrm{s}}$.

Subtracting Eq. (12) from Eq. (13), and using Gibbs model, $U_{\mathrm{t}}^{\mathrm{s}}=U_{0}^{\mathrm{s}}$ and $H_{\mathrm{t}}^{\mathrm{s}}=H_{0}^{\mathrm{s}}$, we have

$\Delta U=U_{\mathrm{t}}-U_{0}=U_{\mathrm{t}}^{\mathrm{a}}+U_{\mathrm{t}}^{\mathrm{g}}-U_{0}^{\mathrm{g}}$

$\Delta H=H_{\mathrm{t}}-H_{0}=H_{\mathrm{t}}^{\mathrm{a}}+H_{\mathrm{t}}^{\mathrm{g}}-H_{0}^{\mathrm{g}}$.

From Eqs. (9), (11) and (14), we have

$\Delta H=\Delta U+\left(p_{\mathrm{t}}^{\mathrm{g}}-p_{0}^{\mathrm{g}}\right) V^{\mathrm{g}}$,

the limiting heat of adsorption is the isosteric heat at pressure tends zero $p_{0}^{\mathrm{g}} \rightarrow 0$. Hence, $\left(p_{\mathrm{t}}^{\mathrm{g}}-p_{0}^{\mathrm{g}}\right) \rightarrow 0$, and $V^{\mathrm{g}}$ is a finite constant. Eq. (15) can be transformed into

$\Delta H_{\text {limit }}=\Delta U$.

Hence, in this case, in order to obtain the limiting heat of adsorption we just need to calculate the change in internal energy of $\mathrm{CH}_{4}$ adsorption on graphene. The variations of the internal energy of $\mathrm{CH}_{4}$ adsorption on monolayer and bilayer graphene were simulated as shown in Fig. A.2. The change in internal energy of $\mathrm{CH}_{4}$ adsorption on monolayer graphene is -5.97 $\mathrm{kcal} / \mathrm{mol}$, and when $\mathrm{CH}_{4}$ adsorption on bilayer graphene, it becomes $-6.38 \mathrm{kcal} / \mathrm{mol}$. The limiting heat of adsorption is $-\Delta H_{\text {limit }}=-\Delta U$, hence the limiting heat of $\mathrm{CH}_{4}$ adsorption on bilayer graphene is larger than adsorption on monolayer graphene.

Experimentally, the isosteric heat of adsorption of $\mathrm{CH}_{4}$ on Woodford shale is $5.23 \mathrm{kcal} / \mathrm{mol}$ [36]. The limiting heat of adsorption of $\mathrm{CH}_{4}$ on shale is $5.72 \mathrm{kcal} / \mathrm{mol}$ [37]. Comparing the $\mathrm{CH}_{4}$ adsorption on monolayer graphene with the $\mathrm{CH}_{4}$ adsorption on shale, the limiting heat of adsorption is very close, and the isosteric heat of adsorption of $\mathrm{CH}_{4}$ on Woodford shale is lower than the limiting heat of adsorption of $\mathrm{CH}_{4}$ adsorption on monolayer graphene. It is a reasonable approximation by showing that $\mathrm{CH}_{4}$ adsorption heat on graphene is similar to that obtained from macroscale experiments on shale. Therefore, it is feasible to investigate the adsorption properties of $\mathrm{CH}_{4}$ on graphene instead of the adsorption on shale in simulations.

\subsection{Adsorption isotherm of $\mathrm{CH}_{4}$ on graphene}

The GCMC simulations were performed to predict the $\mathrm{CH}_{4}$ adsorption isotherm at $300 \mathrm{~K}, 320 \mathrm{~K}, 340 \mathrm{~K}$ and $360 \mathrm{~K}$, in fugacity from $1 \mathrm{MPa}$ to $40 \mathrm{MPa}$, with $2 \mathrm{~nm}, 3 \mathrm{~nm}, 5 \mathrm{~nm}, 7 \mathrm{~nm}, 9 \mathrm{~nm}$ and $11 \mathrm{~nm}$ slit pore sizes, respectively. The density fields of $\mathrm{CH}_{4}$ at $300 \mathrm{~K}$ in the $2 \mathrm{~nm}$ slit pore size in different fugacity are shown in Fig. 2. It shows that $\mathrm{CH}_{4}$ adsorbed on the graphene firstly in low fugacity, and then the free $\mathrm{CH}_{4}$ molecules increase with the increasing fugacity. The $\mathrm{CH}_{4}$ adsorption isotherms for multiple graphene slit pore sizes at different temperatures are shown in Fig. 3.

From these results, we found that adsorbed amounts increase with the decrease of the temperature at the same slit pore size of graphene, and decrease with increasing slit pore size of the graphene. The isotherms in these simulations conform to Langmuir adsorption behavior. It indicates that the $\mathrm{CH}_{4}$ adsorption on the graphene is monolayer adsorption. Therefore, we fit the isotherms with Langmuir equation [38]

$q=q_{\mathrm{m}} \frac{k p}{1+k p}$,

where $q$ is the equilibrium adsorption capacity, $q_{\mathrm{m}}$ is the saturated adsorption capacity, $k$ is the Langmuir equilibrium constant in 1/ MPa. The fitting parameters are shown in Table 1 . The saturated adsorption capacity decreases with the increasing temperature, but it increases with the increasing slit pore size of graphene. As shown in Fig. 4, the Langmuir equilibrium constant decreases with the increasing slit pore size of graphene. The larger the Langmuir equilibrium constant becomes, the stronger the adsorption capacity between adsorbate and adsorbent is. It means that the $\mathrm{CH}_{4}$ molecules much more easily adsorb in the smaller slit pore. In addition, the Langmuir equilibrium constant decreases with the increasing temperature. As the temperature increases, the kinetic energy of the adsorption $\mathrm{CH}_{4}$ increases. This increase leads to the $\mathrm{CH}_{4}$ much easier desorption from the graphene.

In this work the adsorbed amount is the absolute adsorption, which is composed of adsorption phase and gas phase. However, excess adsorption is widely used in the experiment. The excess adsorption is defend as

$q_{\mathrm{e}}=q-\frac{\rho v}{M}$,

where $q$ is the adsorption in mol, $\rho$ is the density of free phase, $v$ is the free volume, $M$ is the molar mass of the gas. Compressibility factor is a useful property for modifying the idea gas law to account for the real gas. In statistical mechanics the description of compressibility factor is 


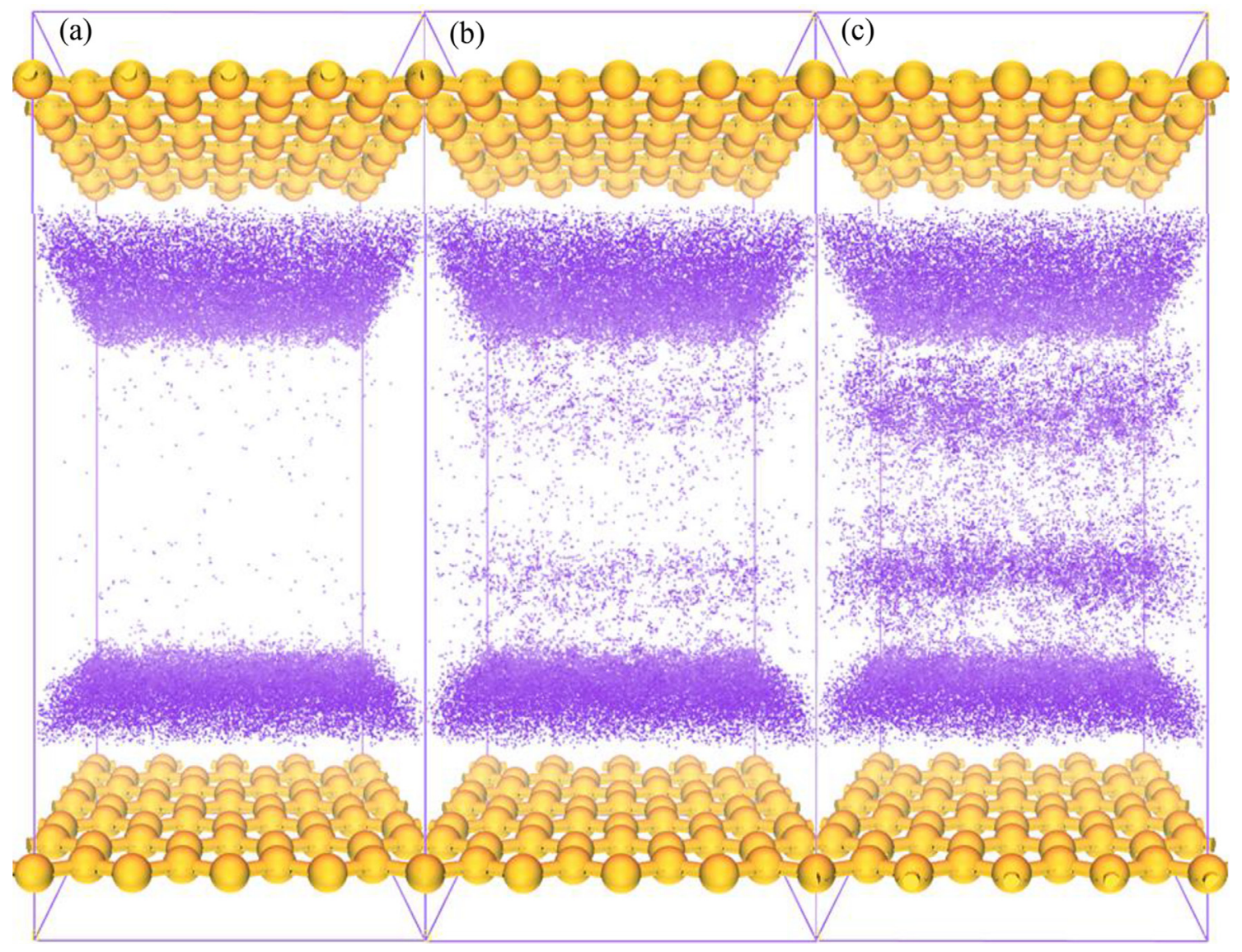

Fig. 2. The density field of $\mathrm{CH}_{4}$ at $300 \mathrm{~K}$ in different fugacity. (a) $1 \mathrm{MPa}$, (b) $3 \mathrm{MPa}$, (c) $8 \mathrm{MPa}$.

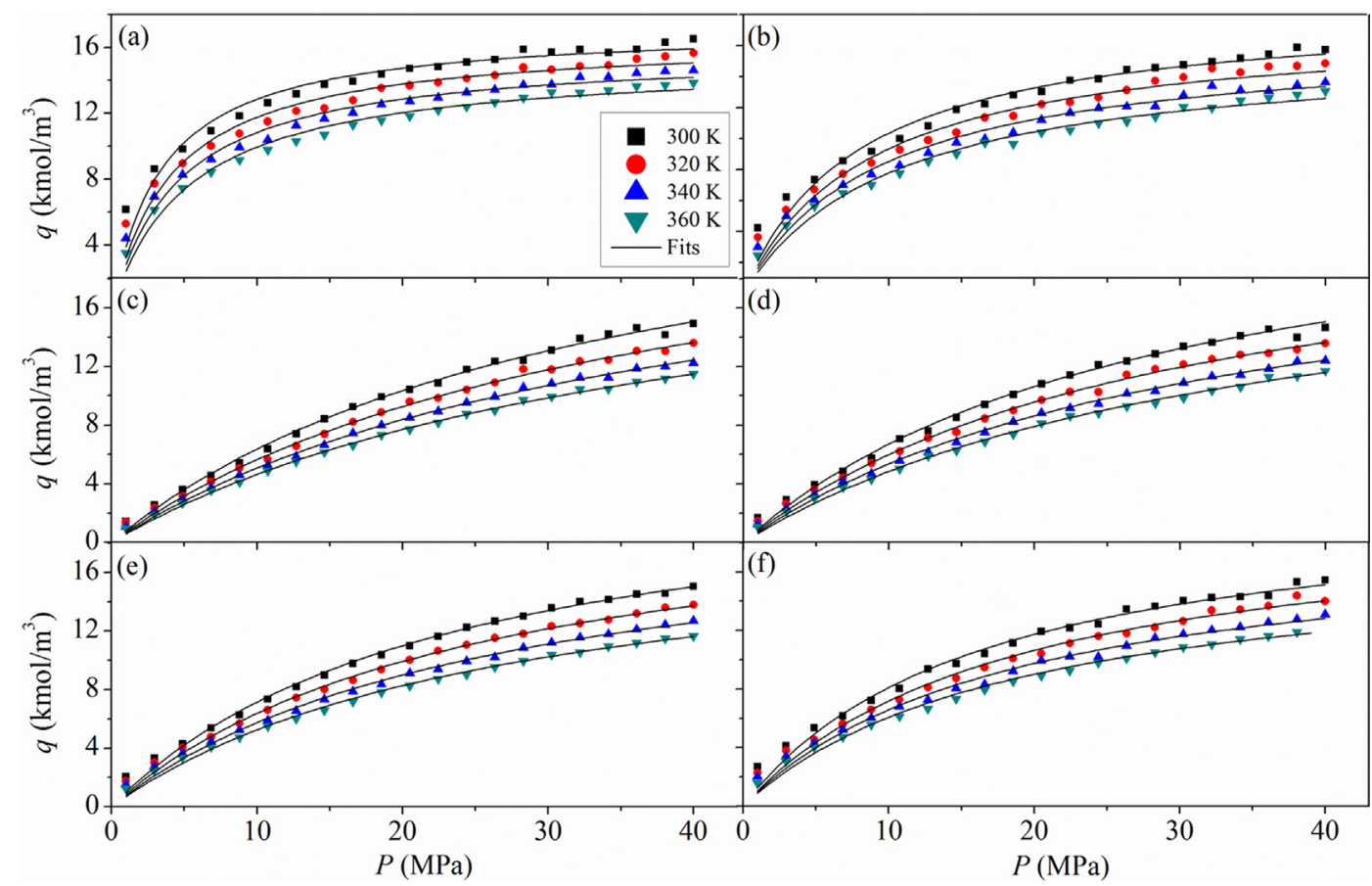

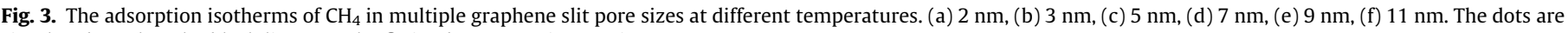
simulated results. The black lines are the fitting by Langmuir equation. 
Table 1

Adsorption parameters with Langmuir fitting.

\begin{tabular}{|c|c|c|c|c|c|c|c|c|}
\hline & \multicolumn{4}{|c|}{$q_{\mathrm{m}}\left(\mathrm{mol} / \mathrm{m}^{3}\right)$} & \multicolumn{4}{|c|}{$k\left(\mathrm{MPa}^{-1}\right)$} \\
\hline & $300 \mathrm{~K}$ & $320 \mathrm{~K}$ & $340 \mathrm{~K}$ & $360 \mathrm{~K}$ & $300 \mathrm{~K}$ & $320 \mathrm{~K}$ & $340 \mathrm{~K}$ & $360 \mathrm{~K}$ \\
\hline $2 \mathrm{~nm}$ & 17287.53 & 16626.94 & 15829.30 & 15241.14 & 0.290 & 0.242 & 0.217 & 0.188 \\
\hline $3 \mathrm{~nm}$ & 18484.64 & 17470.77 & 16481.23 & 15829.66 & 0.127 & 0.115 & 0.107 & 0.097 \\
\hline $5 \mathrm{~nm}$ & 21269.87 & 20555.29 & 18745.23 & 17527.62 & 0.061 & 0.054 & 0.054 & 0.053 \\
\hline $7 \mathrm{~nm}$ & 23808.51 & 22249.17 & 20902.78 & 19541.45 & 0.043 & 0.040 & 0.038 & 0.037 \\
\hline $9 \mathrm{~nm}$ & 25811.14 & 23818.53 & 22258.98 & 21618.39 & 0.035 & 0.034 & 0.032 & 0.029 \\
\hline $11 \mathrm{~nm}$ & 27660.88 & 25832.49 & 24118.11 & 22563.85 & 0.030 & 0.028 & 0.027 & 0.026 \\
\hline
\end{tabular}

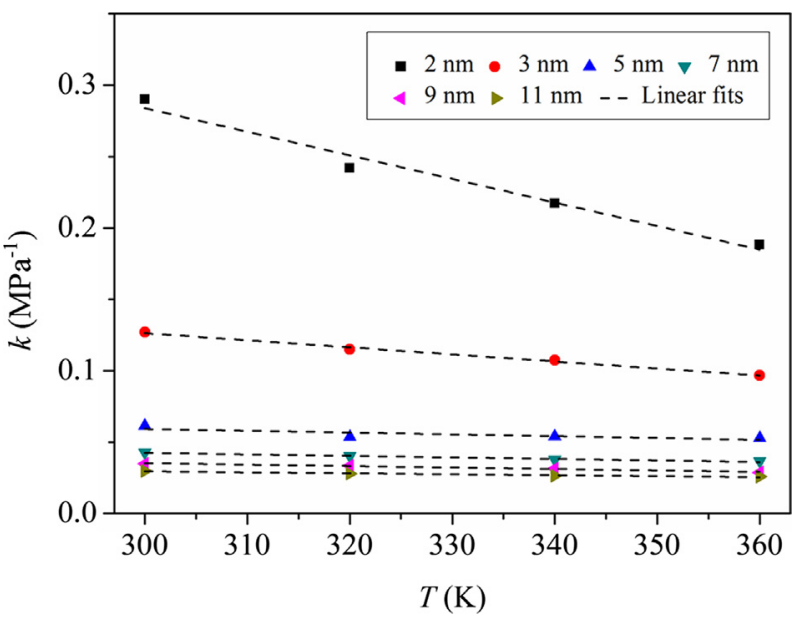

Fig. 4. Variations of the Langmuir equilibrium constant.

$Z=\frac{p v}{n R T}$

where $p$ is pressure of the gas, $n$ is the number of moles. Hence, the number of moles of free phase can be obtained with Eq. (19) then replacing in Eq. (18) we get

$q_{\mathrm{e}}=q-\frac{p v}{Z R T}$.

In addition, the fugacity coefficient of pure gas is defined by

$\varphi=\frac{f}{p}$,

where $f$ is fugacity. Therefore, combining Eq. (20) with Eq. (21) we get

$q_{\mathrm{e}}=q-\frac{f v}{\varphi Z R T}$

In order to obtain the excess adsorbed amount, we need to know the compressibility factor and fugacity coefficient.

The chemical potential $\mu^{\prime}$ is equal to the molar Gibbs free energy $G$, and for a simple compressible substance we have

$\mathrm{d} \mu^{\prime}=\mathrm{d} G=v \mathrm{~d} p-s \mathrm{~d} T$.

In the isothermal process, it becomes

$\mathrm{d} \mu^{\prime}=v \mathrm{~d} p$.

The total differential of chemical potential of a pure real gas is defines as

$\mathrm{d} \mu_{\text {real }}^{\prime}=R T \mathrm{~d} \ln f$.

Combining Eq. (24) with Eq. (25) we get

$\mathrm{d} \ln f=\frac{v \mathrm{~d} p}{R T}$.

The total differential of Eq. (21) is $\mathrm{d} \ln \varphi=\mathrm{d} \ln f-\mathrm{d} \ln p$.

Integration of Eq. (27) from zero to a state pressure $P$ and replace the definition of $Z$ factor in it, we obtain

$\ln \varphi=\int_{0}^{p}\left(\frac{v}{R T}-\frac{1}{p}\right) \mathrm{d} p=\int_{0}^{p} \frac{Z-1}{p} \mathrm{~d} p$.

In addition, based on a virial equation of state, the approach to establishing $Z(T, p)$ is

$Z(T, p)=1+a(T) p+b(T) p^{2}+c(T) p^{3}+\cdots$,

where $a(T)$ and $b(T)$ are related to the temperature of $\mathrm{CH}_{4}$. Hence, these coefficients, in different temperature, can be fitted by

$p v=n\left(1+\mathrm{a} p+\mathrm{b} p^{2}+\mathrm{cp}^{3}\right) R T$.

We chose the first three orders of virial equation of state. Then the integral in Eq. (28) can be evaluated

$$
\begin{aligned}
\ln \frac{f}{p} & =\int_{0}^{P} \frac{Z-1}{p} \mathrm{~d} p=\int_{0}^{p} \frac{\mathrm{a} p+\mathrm{b} p^{2}+\mathrm{c} p^{3}}{p} \mathrm{~d} p \\
& =\mathrm{a} p+\frac{\mathrm{b} p^{2}}{2}+\frac{\mathrm{c} p^{3}}{3} .
\end{aligned}
$$

It can be written as

$f=p e^{a p+\frac{b p^{2}}{2}+\frac{p^{3}}{3}}$.

The fitting results, $\mathrm{CH}_{4}$ in $300 \mathrm{~K}, 320 \mathrm{~K}, 340 \mathrm{~K}$ and $360 \mathrm{~K}$ with pressure from $1 \mathrm{MPa}$ to $40 \mathrm{MPa}$, are shown in Fig. 5. Hence, we can plot the function of Eq. (32) with the fitting coefficients as shown in Fig. 6.

By numerically solving Eq. (32), we can transform the fugacity to pressure. And then we obtain the excess adsorption with the pressure $p$ and the corresponding absolute adsorption $q$ by Eq. (20). Hence, the relationship between fugacity and absolute adsorption can be turned into pressure and excess adsorption. The excess adsorption isotherms of $\mathrm{CH}_{4}$ in $2 \mathrm{~nm}$ slit pore size graphene at $300 \mathrm{~K}, 320 \mathrm{~K}, 340 \mathrm{~K}$ and $360 \mathrm{~K}$ are shown in Fig. 7. Therefore, the results of simulation and experiment can be compared. From these results we found that excess adsorbed amount increases with the decrease of the temperature in $2 \mathrm{~nm}$ slit pore size of graphene. And the excess adsorption cannot be obviously improved when the pressure more than 11-12 MPa. It has the same tendency in the model of kerogen from the Woodford and Green River shale samples [39]. Experimentally, the excess adsorbed amount increases at first and then stop increasing after 11-12 MPa in Tarrant A-3 shale and Blakely \#1 shale [36]. Through the comparison of the experimental and simulative results, their changing tendency is in agreement qualitatively. Therefore, it also shows that it is feasible to choose graphene as a model of shale in simulations. In addition, the simulation results can give an instruction to product directly. 


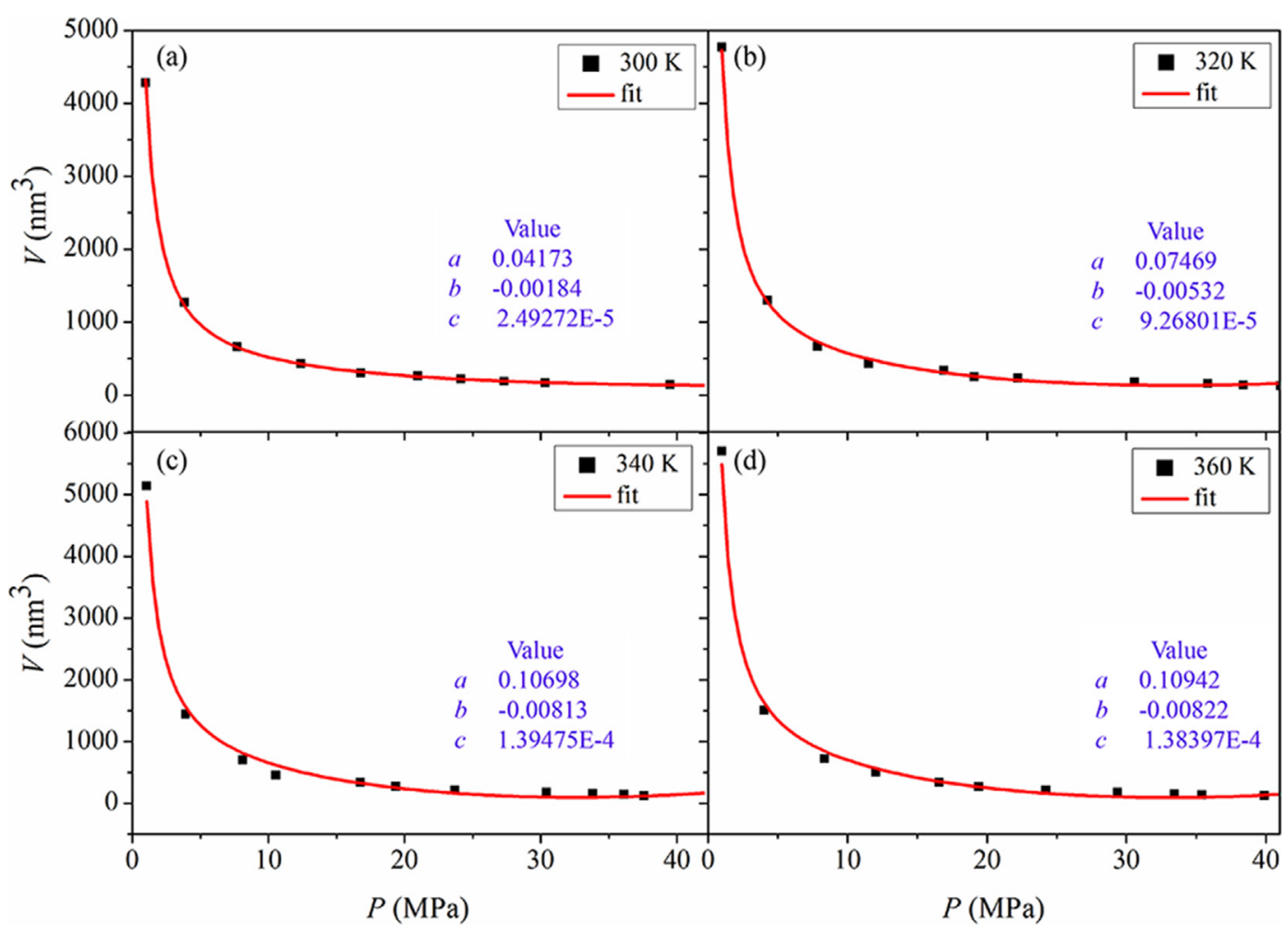

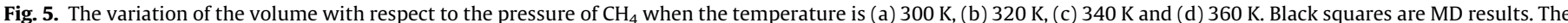

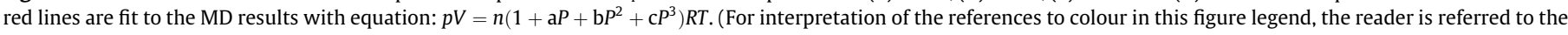
web version of this article.)

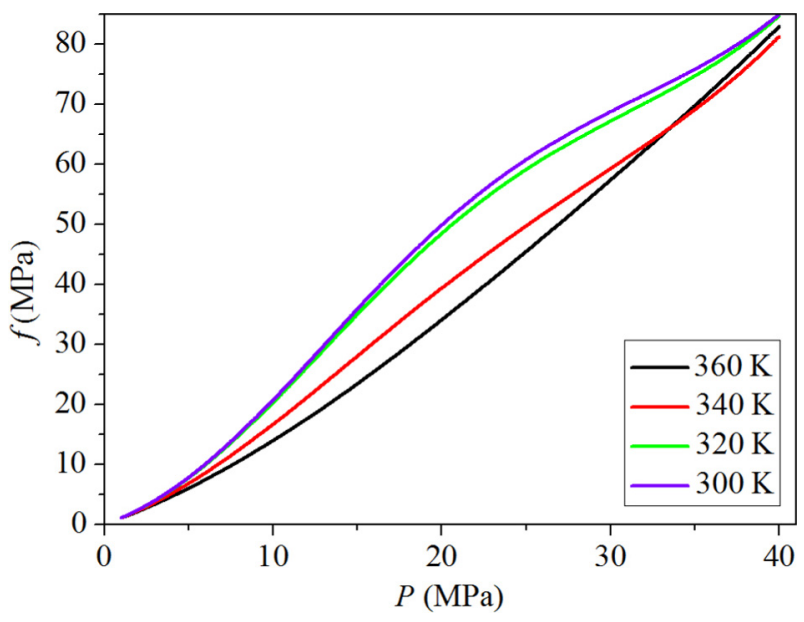

Fig. 6. The variation between fugacity and pressure of $\mathrm{CH}_{4}$ in $300 \mathrm{~K}, 320 \mathrm{~K}, 340 \mathrm{~K}$ and $360 \mathrm{~K}$.

\subsection{Isosteric adsorption heat of $\mathrm{CH}_{4}$ on graphene}

Isosteric adsorption heat is commonly used in the characterization of gas adsorption. The isoteric adsorption heats of $\mathrm{CH}_{4}$ in multiple graphene slit pore sizes at different temperatures were shown in Fig. 8. The graph's horizontal axis shows the absolute adsorption, hence, the adsorption heat decreased at first and later flattened particularly evident in 3-11 nm pores. It indicates that the adsorption heat decreases with increasing coverage. Actually, the adsorption heat is independent of coverage in ideal adsorption. But for real adsorption, adsorption heat changes with coverage because

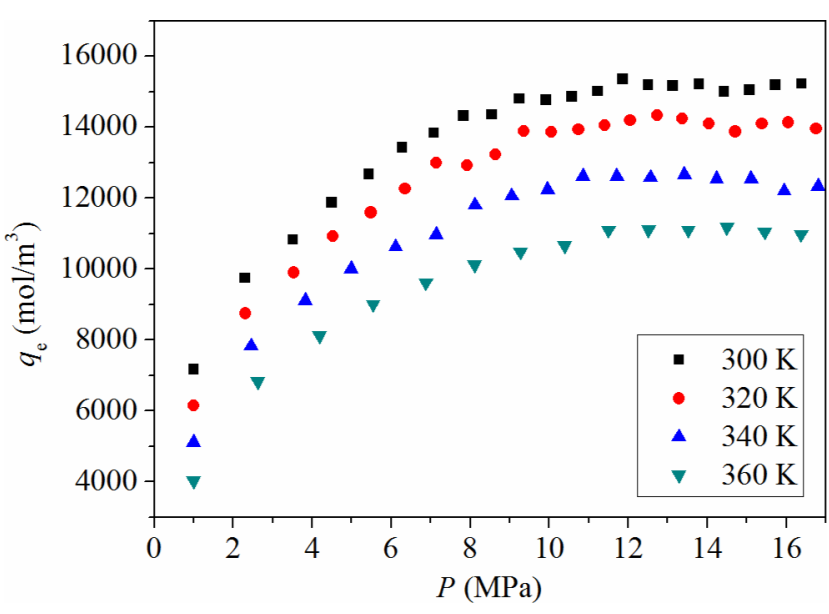

Fig. 7. The excess adsorption isotherms of $\mathrm{CH}_{4}$ in $2 \mathrm{~nm}$ slit pore size graphene.

of the surface heterogeneity. In the beginning, $\mathrm{CH}_{4}$ adsorbs at the active adsorption site which gives out more heat than the $\mathrm{CH}_{4}$ adsorbs at the inactive adsorption site.

From these results, we found that the adsorption heat of $\mathrm{CH}_{4}$ in $2 \mathrm{~nm}$ slit pore size graphene almost unchanged when the absolute adsorption increase. Because the $2 \mathrm{~nm}$ pore is so small that the $\mathrm{CH}_{4}$ molecules can easily adsorb at the graphene surface and then quickly reach saturation. In addition, the adsorption heat decreases with the increasing slit pore size of graphene, which means that the adsorption capacity of smaller pore is stronger than lager pore. This property is consistent with the experimental result [40]. Moreover, the adsorption heat decreases with increasing temperature. 


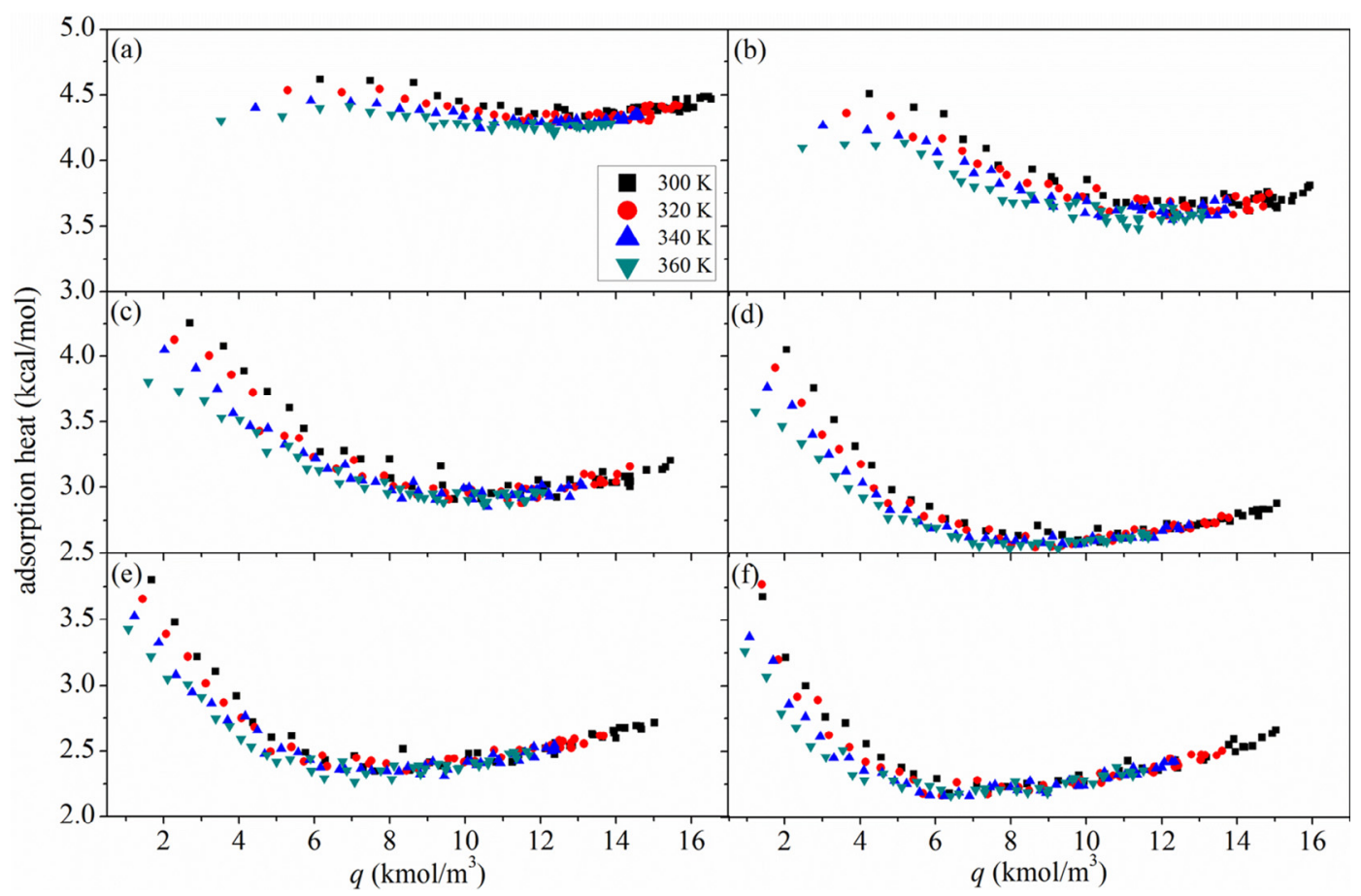

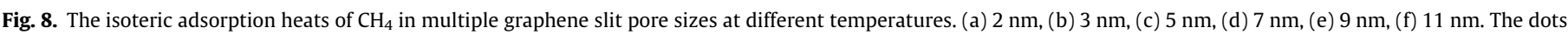
are simulated results.

Because the higher the temperature becomes, the faster the motion of the molecule is. So the adsorption capacity decreases with the increasing temperature.

\section{Conclusions}

For the first time, the interaction potential between multilayer graphene and $\mathrm{CH}_{4}$ were investigated. The results indicate that the first two layers of graphene play the main role of the interaction potential between multilayer graphene and $\mathrm{CH}_{4}$. We can just consider investigating the interaction between $\mathrm{CH}_{4}$ with monolayer graphene $(85.5 \%)$ or bilayer graphene (96.6\%). The limiting heat of $\mathrm{CH}_{4}$ adsorption on monolayer graphene is $5.97 \mathrm{kcal} / \mathrm{mol}$, and that of $\mathrm{CH}_{4}$ adsorption on bilayer graphene becomes $6.38 \mathrm{kcal} / \mathrm{mol}$. The limiting heat of adsorption on monolayer graphene is very close to the adsorption heat with the $\mathrm{CH}_{4}$ adsorption on shale. Therefore, it proves that it is feasible to investigate the adsorption properties of $\mathrm{CH}_{4}$ on graphene instead of adsorption on shale in simulations.

We found that adsorbed amount increases with the decrease of the temperature at the same slit pore size of graphene, and decrease with increasing slit pore size of the graphene. The Langmuir equilibrium constant decreases with the increasing slit pore size of graphene. Hence, $\mathrm{CH}_{4}$ is much easier to be adsorbed in the smaller pore. In addition, the Langmuir equilibrium constant decreases with the increasing temperature. The adsorption heat decreases with increasing temperature because the higher the temperature becomes, the faster the motion of the molecule is. So the adsorption capacity decreases with the increasing temperature. Based on theoretical analysis, we provide a way to transform fugacity and absolute adsorption into pressure and excess adsorption, respectively, which is convenient for combining simulation and experiment. These results show good accordance with existing experiments and could help to understand the shale gas adsorption on shale. Consequently, graphene can be a good candidate as a model of shale in simulations.

\section{Acknowledgments}

This research was supported in part by the National Natural Science Foundation of China (NSFC, Grant No. U1562105), and by the Chinese Academy of Sciences (CAS) through CAS Interdisciplinary Innovation Team Project, the CAS Key Research Program of Frontier Sciences (Grant No. QYZDJ-SSW-JSC019) and the CAS Strategic Priority Research Program (Grant No. XDB22040401).

\section{Appendix A. Interaction potential between $\mathrm{CH}_{4}$ and graphene}

The interaction between $\mathrm{CH}_{4}$ and graphene is $\mathrm{LJ}$ potential:

$E(r)=4 \varepsilon\left[\left(\frac{\sigma}{r}\right)^{12}-\left(\frac{\sigma}{r}\right)^{6}\right]$,

where $\varepsilon$ is the well depth, $\sigma$ is the value of $r$ at which $E(r)=0$. The number density of the graphene surface is $\rho=N / S=3.8 \times 10^{19} \mathrm{~m}^{-2}$ (number of particles $N$ divided by the surface area $S$ ). Here, the total interaction between single atomic layer and adsorbate is

$$
\begin{aligned}
E(z) & =\rho \int_{0}^{2 \pi} \mathrm{d} \theta \int_{0}^{\infty}\left[4 \varepsilon \sigma^{12}\left(r_{0}^{2}+z^{2}\right)^{-6}-4 \varepsilon \sigma^{6}\left(r_{0}^{2}+z^{2}\right)^{-3}\right] r_{0} \mathrm{~d} r_{0} \\
& =8 \varepsilon \pi \rho \sigma^{2}\left(\frac{\sigma^{10}}{10 z^{10}}-\frac{\sigma^{4}}{4 z^{4}}\right)
\end{aligned}
$$

where $z$ is the adsorption distance, $r_{0}$ is the distance from the center. In order to investigate the effect of the number of graphene layers on the interaction potential, we have explored the $\mathrm{CH}_{4}$ adsorbs on multilayer graphene as shown in Fig. A.1. Hence, the interaction between 1 st layer and a molecule is 


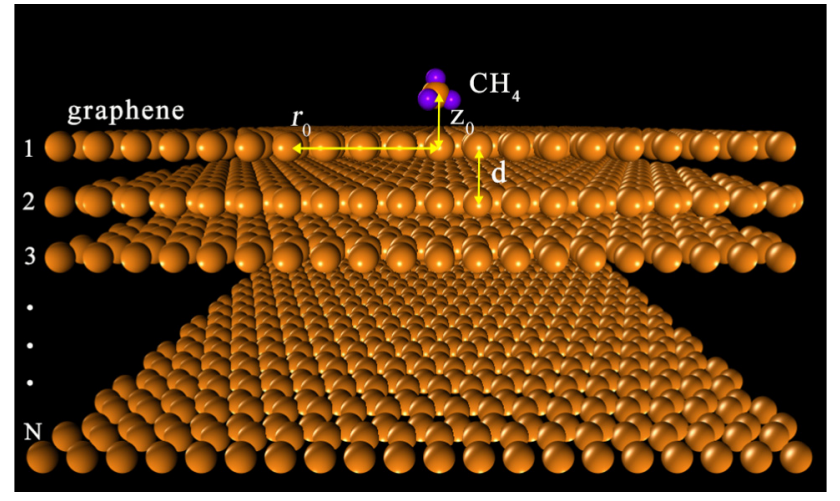

Fig. A1. $\mathrm{CH}_{4}$ adsorbs on multilayer graphene. $\mathrm{z}_{0}$ is the adsorption distance, $r_{0}$ is the distance from the center, $\mathrm{d}$ is the space between bilayer of graphene.

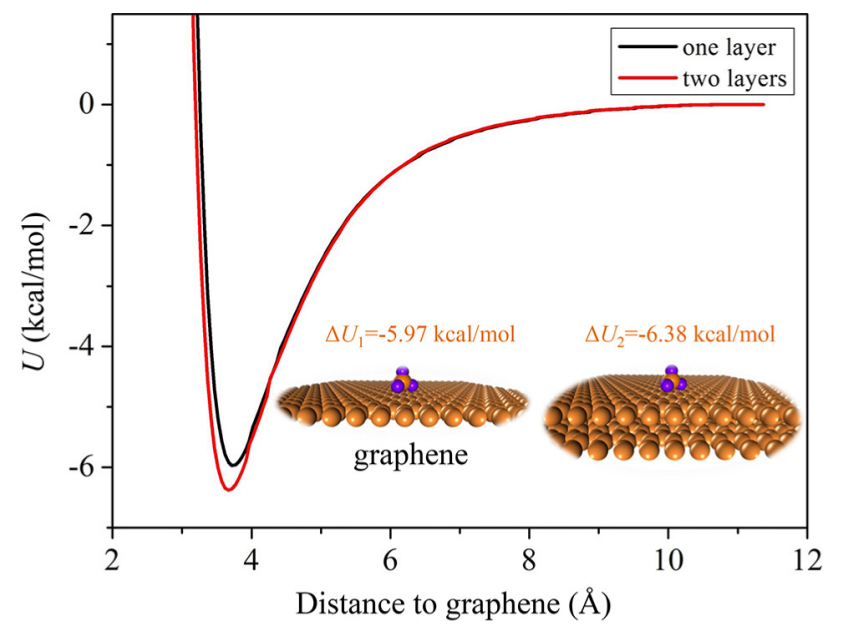

Fig. A2. Variations of the internal energy in the $\mathrm{CH}_{4}$ adsorption processes. The black line is the case of monolayer graphene. The red line is the case of bilayer graphene. (For interpretation of the references to colour in this figure legend, the reader is referred to the web version of this article.)

$E_{1}=8 \varepsilon \pi \rho \sigma^{2}\left(\frac{\sigma^{10}}{10 z_{0}^{10}}-\frac{\sigma^{4}}{4 z_{0}^{4}}\right)$

The interaction between $n$th layer and a molecular is

$E_{n}=8 \varepsilon \pi \rho \sigma^{2}\left\{\frac{\sigma^{10}}{10\left[z_{0}+(n-1) d\right]^{10}}-\frac{\sigma^{4}}{4\left[z_{0}+(n-1) d\right]^{4}}\right\}$.

Therefore, the total interaction between multilayer graphene and a $\mathrm{CH}_{4}$ is $E_{\text {total }}=\sum_{n=1}^{\mathrm{N}} E_{n}$. The parameter $\sigma$ is $3.68 \AA$. The equilibrium distance between $\mathrm{CH}_{4}$ and graphene $z_{0}$ is $3.49 \AA$. And the space between bilayer graphene $d$ is $3.6 \AA$. Hence, we have $E_{1} / E_{\text {total }} \approx 85.5 \%$ and $\left(E_{1}+E_{2}\right) / E_{\text {total }} \approx 96.6 \%$. The results indicate that the first bilayer of graphene plays the main role of the interaction potential between multilayer graphene and $\mathrm{CH}_{4}$. Hence, if we want to explore the adsorption properties of $\mathrm{CH}_{4}$ on multilayer graphene, we can just consider investigating the interaction between $\mathrm{CH}_{4}$ and monolayer or bilayer graphene. The variations of the internal energy of $\mathrm{CH}_{4}$ adsorption on monolayer and bilayer graphene were simulated as shown in Fig. A.2.

\section{References}

[1] A. Burnham, J. Han, C.E. Clark, M. Wang, J.B. Dunn, I. Palou-Rivera, Life-cycle greenhouse gas emissions of shale gas, natural gas, coal, and petroleum, Environ. Sci. Technol. 46 (2) (2011) 619-627.
[2] J.B. Curtis, Fractured shale-gas systems, AAPG Bull. 86 (11) (2002) 1921-1938.

[3] R.W. Howarth, A. Ingraffea, T. Engelder, Natural gas: Should fracking stop?, Nature 477 (7364) (2011) 271-275

[4] J.D. Hughes, Energy: A reality check on the shale revolution, Nature 494 (7437) (2013) 307-308.

[5] C. Mcglade, J. Speirs, S. Sorrell, Unconventional gas - A review of regional and global resource estimates, Energy 55 (2013) 571-584.

[6] R. Heller, J. Vermylen, M. Zoback, Experimental investigation of matrix permeability of gas shales, AAPG Bull. 98 (5) (2014) 975-995.

[7] A. Al Hinai, R. Rezaee, L. Esteban, M. Labani, Comparisons of pore size distribution: A case from the Western Australian gas shale formations, J. Unconv. Oil Gas Resour. 8 (2014) 1-13.

[8] F. Javadpour, Nanopores and apparent permeability of gas flow in mudrocks (shales and siltstone), J. Can. Pet. Technol. 48 (08) (2009) 16-21.

[9] R.A. Kerr, Natural gas from shale bursts onto the scene, Science 328 (5986) (2010) 1624-1626.

[10] D.L. Shaffer, L.H. Arias Chavez, M. Ben-Sasson, S. Romero-Vargas Castrillón, N. Y. Yip, M. Elimelech, Desalination and reuse of high-salinity shale gas produced water: drivers, technologies, and future directions, Environ. Sci. Technol. 47 (17) (2013) 9569-9583.

[11] E. Ghanbari, H. Dehghanpour, Impact of rock fabric on water imbibition and salt diffusion in gas shales, Int. J. Coal Geol. 138 (2015) 55-67.

[12] S. Kang, E. Fathi, R.J. Ambrose, et al., Carbon dioxide storage capacity of organicrich shales, SPE J. 16 (4) (2011) 842-855.

[13] R. Heller, M. Zoback, Adsorption of methane and carbon dioxide on gas shale and pure mineral samples, J. Unconv. Oil Gas Resour. 8 (2014) 14-24.

[14] C. Oldenburg, K. Pruess, S.M. Benson, Process modeling of $\mathrm{CO}_{2}$ injection into natural gas reservoirs for carbon sequestration and enhanced gas recovery, Energy Fuels 15 (2) (2001) 293-298.

[15] F. Javadpour, D. Fisher, M. Unsworth, Nanoscale gas flow in shale gas sediments, J. Can. Pet. Technol. 46 (10) (2007) 55-61.

[16] C.M. Freeman, G.J. Moridis, T.A. Blasingame, A numerical study of microscale flow behavior in tight gas and shale gas reservoir systems, Transp. Porous Media 90 (1) (2011) 253-268.

[17] Y.M. Metwally, C.H. Sondergeld, Measuring low permeabilities of gas-sands and shales using a pressure transmission technique, Int. J. Rock Mech. Min. Sci. 48 (7) (2011) 1135-1144.

[18] C.R. Clarkson, N. Solano, R.M. Bustin, A.M.M. Bustin, G.R.L. Chalmers, L. He, Y.B Melnichenko, A.P. Radliński, T.P. Blach, Pore structure characterization of North American shale gas reservoirs using USANS/SANS, gas adsorption, and mercury intrusion, Fuel 103 (2013) 606-616.

[19] H. Sone, M.D. Zoback, Mechanical properties of shale-gas reservoir rocks Part 1: Static and dynamic elastic properties and anisotropy, Geophysicists 78 (5) (2013) D381-D392.

[20] P. Chareonsuppanimit, S.A. Mohammad, R.L. Robinson, K.A. Gasem, Highpressure adsorption of gases on shales: measurements and modeling, Int. J. Coal Geol. 95 (2012) 34-46.

[21] U. Kuila, M. Prasad, Specific surface area and pore-size distribution in clays and shales, Geophys. Prospect. 61 (2) (2013) 341-362.

[22] H. Gan, S. Nandi, P. Walker, Nature of the porosity in American coals, Fuel 51 (4) (1972) 272-277.

[23] R.G. Loucks, R.M. Reed, S.C. Ruppel, D.M. Jarvie, Morphology, genesis, and distribution of nanometer-scale pores in siliceous mudstones of the Mississippian Barnett Shale, J. Sediment. Res. 79 (12) (2009) 848-861.

[24] A. Firoozabadi, Thermodynamics and Applications of Hydrocarbons Energy Production, McGrew Hill Professional, New York, 2015.

[25] R.J. Ambrose, R.C. Hartman, M. Diaz Campos, I.Y. Akkutlu, C. Sondergeld, In New pore-scale considerations for shale gas in place calculations, in: SPE Unconventional Gas Conference, Society of Petroleum Engineers, 2010.

[26] K. Mosher, J. He, Y. Liu, E. Rupp, J. Wilcox, Molecular simulation of methane adsorption in micro-and mesoporous carbons with applications to coal and gas shale systems, Int. J. Coal Geol. 109 (2013) 36-44.

[27] Y. Liu, J. Wilcox, Effects of surface heterogeneity on the adsorption of $\mathrm{CO}_{2}$ in microporous carbons, Environ. Sci. Technol. 46 (3) (2012) 1940-1947.

[28] S. Wang, Q. Feng, F. Javadpour, T. Xia, Z. Li, Oil adsorption in shale nanopores and its effect on recoverable oil-in-place, Int. J. Coal Geol. 147-148 (2015) 924.

[29] H.A. Wu, J. Chen, H. Liu, Molecular dynamics simulations about adsorption and displacement of methane in carbon nanochannels, J. Phys. Chem. C 199 (2015) 13652-13657.

[30] O.Z. Yuan, X.Y. Zhu, K. Lin, Y.P. Zhao, Molecular dynamics simulations of the enhanced recovery of confined methane with carbon dioxide, Phys. Chem. Chem. Phys. 17 (47) (2015) 31887-31893.

[31] X.Y. Zhu, Y.P. Zhao, Atomic mechanisms and equation of state of methane adsorption in carbon nanopores, J. Phys. Chem. C 118 (31) (2014) 17737 17744.

[32] K. Lin, Q.Z. Yuan, Y.P. Zhao, C.M. Cheng, Which is the most efficient candidate for the recovery of confined methane: Water, carbon dioxide or nitrogen? Extreme Mech Lett. 9 (2016) 127-138.

[33] S. Plimpton, Fast parallel algorithms for short-range molecular dynamics, J. Comput. Phys. 117 (1) (1995) 1-19.

[34] P. Dauber-Osguthorpe, V.A. Roberts, D.J. Osguthorpe, J. Wolff, M. Genest, A.T. Hagler, Structure and energetics of ligand binding to proteins: Escherichia coli dihydrofolate reductase-trimethoprim, a drug-receptor system, Proteins 4 (1) (1988) 31-47. 
[35] D.M. Ruthven, Principles of Adsorption and Adsorption Processes, John Wiley \& Sons, 1984.

[36] T. Zhang, G.S. Ellis, S.C. Ruppel, K. Milliken, R. Yang, Effect of organic-matter type and thermal maturity on methane adsorption in shale-gas systems, Org. Geochem. 47 (2012) 120-131.

[37] F. Yang, Z. Ning, R. Zhang, H. Zhao, T. Zhao, B. He, Comparison analysis on model of methane adsorption isotherms in shales, Coal Sci. Technol. 39 (07) (2014) 1327-1332.
[38] I. Langmuir, The adsorption of gases on plane surfaces of glass, mica and platinum, J. Am. Chem. Soc. 40 (9) (1918) 1361-1403.

[39] Z. Jin, A. Firoozabadi, Thermodynamic modeling of phase behavior in shale media, SPE J. 21 (1) (2016) 190-207.

[40] F. Yang, Z. Ning, H. Liu, Fractal characteristics of shales from a shale gas reservoir in the Sichuan Basin, China, Fuel 115 (2014) 378-384. 